En resumidas cuentas, Luna emplea sus estratagemas satíricas con una fusión de conciencia ética e invención literaria que traduce perfectamente un discernimiento moral y político en una obra de arte única. O sea que la sociedad ya no podía ser "redefinida" irónicamente ${ }^{\mathbf{3 1}}$, sino que tenía que ser sutilmente invadida, subvertida y reconstruida, cosa sólo posible literariamente en aquel entonces para algún "raro inventor", o para los que lanzaban sus granadas desde un concreto "buen puerto" como París. Esta Segunda Parte del Lazarillo de Tormes es clara muestra de la fuerza de lo cómico como subversión y ataque, que no por eso pierde su calidad mágica de arte eficaz.

State University of New York at Stony Brook.

Alan Francis.

\title{
CÉSAR VALLEJO: DOS POEMAS ELEGÍACOS
}

Los trabajos críticos sobre César Vallejo coinciden, en general, al estudiar el tema de la muerte en su poesía como uno de los temas capitales y quizá el más constante entre los que se mantienen desde los $\mathrm{He}$ raldos negros hasta España, aparta de mi este cáliz, si bien sujeto a las variantes del estilo y de la visión poética del autor. Estamos por lo tanto, ante un elemento que da unidad a su poesía y al mismo tiempo puede ser tomado como piedra de toque que descubra sus cambios profundos. El punto que la crítica, en este caso, ha dejado casi siempre al margen es la demostración de cómo esas variantes del tema de la muerte tienen lugar, antes que nada, en la materialidad del texto poético; ésa es la ubicación olvidada de los cambios conceptuales que todos los críticos señalan tan puntualmente. Si se toman dos poemas, distantes entre sí por el tiempo en que fueron escritos, pero ambos surgidos en torno a la muerte de un ser próximo al poeta (su hermano Miguel, su amigo Alfonso de Silva) y se comparan sus textos y la utilización del lenguaje que en ellos se hace, seguramente es posible desvelar alguna parte de

GERD Rótzer se refiere a las raíces históricas de este tipo de escena, mencionando la frecuencia de tales acusaciones arbitrarias (Picaro-Landtstörtzer-Simplicius, Darmstadt, 1972, pp. 32-33). Para otro caso trágicamente real, hasta el punto de parecer novela, véase Ángela Selke, El Santo Oficio de la Inquisición. Proceso de Fr. Fran. cisco Ortiz (1529-1532), Madrid, 1968. Cf. también Julio Caro Baroja, Los judios en la España moderna y contemporánea, Madrid, 1961, t. 1, pp. 299 ss. HeNRY KA. MEN, The Spanish Inquisition, London, 1965, pp. 177 ss. Es interesante notar, al terminar este estudio del arte satírico de Luna, la manera en que la crítica de toda una tabla de valores sociales refleja las posturas problemáticas de cierto sector ds escritores como Carlos García o Antonio Enríquez Gómez frente a las tendencias acomodaticias de novelistas como Castillo Solórzano o Francisco Santos. Acerca de la actitud de éste para con la Inquisición, puede verse la edición y estudio de Julio Rodríguez Puértolas, Francisco Santos, El no importa de España y La verdad en el potro, London, 1973, pp. Ivii-lxvi. 149-166.

31 Cf. Stepren Gilman, "The death of Lazarillo de Tormes", PMLA, 81 (1966), 
la propiedad que une y separa las dos visiones y comunicaciones del tema de la muerte.

El primer poema, "A mi hermano Miguel", forma parte de un grupo muy uniforme bajo el título general de "Canciones del hogar". Aparte de los elementos temáticos (personajes, geografía, sentimientos...) que les dan unidad, su estilo ha venido siendo considerado de una particular simplicidad, hasta el punto de que se piensa que "the sentiments that they needto convey are really more important than the style in which they are expressed"'; todo lo cual no impide a muchos críticos concentrar su aprecio por los Heraldos negros en estos pocos poemas finales.

El poema "A mi hermano Miguel" destaca, en ese contexto del "hogar", el tema de la muerte. Es una elegía de diez y nueve versos divididos en cuatro estrofas. El autor no desarrolla ningún profundo concepto de la muerte ("falta sin fondo", "sombra en el alma", no ofrecen ninguna novedad: ya Bécquer escribía cincuenta años antes, "padecer es vivir", rima LVI, "cayó sobre mi espíritu la noche", rima XIII, como también "He condensado un siglo en cada dia", LVII, y "amargo placer", LXVIII, que recuerdan frecuentes versos de Vallejo); no trae las ideas de consuelo donde la elegía tradicional incluía sus novedades; tampoco elabora metáforas de una especial originalidad: el cuerpo principal del poema narra la muerte como un juego al escondite, entre dos niños hermanos, con tristes consecuencias. Ahora bien, a mi modo de ver, en el poema hay una originalidad en el tratamiento de la muerte que radica en la pura materialidad del estilo, en la disposición de unos elementos significantes, que son las personas y los tiempos verbales, cuyos significados no cumplen otro papel que el de soportes básicos o verosimiles tradicionales. La forma en que esta disposición de elementos significantes se lleva a cabo es la siguiente: en las dos primeras estrofas del poema se crea un patrón según el cual el presente de indicativo y subjuntivo (estoy, haces, me acuerdo / me escondo, espero, des, te ocultas, doy, me acuerdo) se reparten entre la primera y la segunda persona del singular. Este presente ocupa los primeros versos de cada estrofa. Los dos versos finales, en cambio, introducidos en ambos casos por "me acuerdo", llevan el verbo en pretérito perfecto de indicativo y en tercera persona del singular o primera persona del plural (jugábamos, acariciaba / haciamos llorar). Si se considera esto un patrón es porque se repite fielmente en dos estrofas sucesivas, creando una atmósfera a base de ese determinado, seguro ritmo de personas y tiempos verbales.

En la tercera, penúltima estrofa, el autor descubre el significado de la metáfora del juego: la muerte. Pero el autor no lo descubre con significados expresos (no se dice la palabra "muerte"; el término "juego", que había aparecido en las dos estrofas anteriores, desaparece en ésta) sino más bien destruyendo sistemáticamente el patrón que había creado en aquellas dos primeras estrofas: los primeros versos utilizan tres tiempos distintos, que no les corresponden según el antiguo patrón (el pretérito indefinido, el imperfecto y el perfecto: escondiste, estabas, se ha aburrido) con personas que correspondian al presente (segunda) y al

1 D. P. Gallagher, Modern Latin American literature, Oxford, 1973, p. 16. 
imperfecto (tercera del singular), mientras la cadencia final, no introducida ya por "me acuerdo", ha abandonado el imperfecto por un presente de indicativo en la persona que no le corresponde, la tercera del singular: "cae". Sin embargo, la ruptura no queda rotundamente indicada sólo por la presencia de elementos nuevos, contradictores; tanto o más colabora a ella la ausencia total de los presentes de indicativo en primera persona del singular, que era el elemento dominante de las dos primeras estrofas. Si tenemos ahora en cuenta que lo único que se repite en esta estrofa, de las dos anteriores, son significados como "esconderse", "ocultarse", "no encontrar" (sinónimo de "no dar con"), se puede confirmar que la originalidad en la expresión de la muerte como ruptura se apoya en el montaje de los elementos significantes; los significados, en su simplicidad, repetidos, como meros soportes, cumplen la función básica del verosimil "juego del escondite inacabado".

Posiblemente el elemento que da mayor unidad a todo el poema es su carácter narrativo: se desarrolla una sola metáfora, la historia de un juego, una tarde. En un momento determinado, y sin perder el carácter narrativo, se introduce una cierta explicación de la metáfora. Después, al llegar el último instante, una estrofa de sólo dos versos trata de recuperar el estricto carácter narrativo de la metáfora, prescindiendo aparentemente de la explicación que se acaba de dar (qué es la muerte; por lo tanto, se quiere prescindir de la muerte) para darle su último dato informador: hay tres presentes, dos de imperativo y uno de indicativo en tercera persona; hay, pues, una especie de violencia que no consigue, en absoluto, recuperar el patrón y las cadencias que las dos primeras estrofas habían logrado crear. El último dato de la metáfora muerte = juego al escondite resulta, pues, muerte $=$ juego al escondite incompleto, inacabado, irrecuperado, al mismo tiempo que se solicita urgentemente esa recuperación (imperativo).

Esta disposición de los elementos verbales no consiste en una serie de pistas cuidadosamente ocultas en la morfologia y la sintaxis del texto del poema; por el contrario, todos los elementos gramaticales (sustantivos, adverbios, ... etc.) la sostienen manifiestamente. Por ejemplo, la repetición del patrón que se vio en las dos primeras estrofas se traduce también en los siguientes términos:

$$
\begin{aligned}
& \text { Hoy - Ahora } \\
& \text { esta hora - estas oraciones vespertinas } \\
& \text { jugábamos - juego } \\
& \text { nos haces - nos hacíamos }
\end{aligned}
$$

Más aún, entre la primera y la segunda estrofa hay una relación como de pregunta a respuesta, como de enigma a clave. En la primera estrofa se menciona un juego ("jugábamos") sin decirnos cuál, y un reproche/ consuelo de la madre ("nos acariciaba: 'Pero, hijos...",; la misma "cantora y linda cólera materna" de Trilce LII), sin decirnos por qué. La segunda estrofa no es, en definitiva, más que la respuesta a esos enigmas, por el mismo orden en que han sido propuestos: el juego es 
el del escondite, largamente explicado; el porqué del reproche/consuelo, "nos hacíamos llorar".

Hemos visto que la estrofa tercera viene a ser como una cuña explicativa de las dos anteriores; la relación que mantiene con ellas es, en cierto sentido, como la que hay entre los ríos y la mar de la vieja metáfora sobre la muerte: "tarde" desemboca en "noche" y "tardes extintas", "nos hacíamos llorar" desemboca en "triste", "yo no doy contigo" desemboca en "aburrido". En la cuarta estrofa (los dos últimos versos), que trata de recuperar y completar la metáfora de los dos primeros, hemos visto un absoluto fracaso en el intento de conjurar la muerte; los únicos elementos recuperados, al nivel del discurso, son los términos "hermano" (de la segunda estrofa) y "mamá" (de la primera); en cambio, la acción se ha detenido, los elementos verbales continúan dentro del caos impuesto por la estrofa tercera, el caos de la muerte, del "sin fondo"; pero los elementos verbales son los que determinan, los que estructuran; no hay, pues, recuperación.

Aparte de todos los indicios de muerte que van incluidos en los elementos vistos hasta ahora ("llorar", "tarde", "triste"... Véase el "vocabulario fúnebre" de los Heraldos negros que acumula Coyné2), hay dos versos del poema que son responsables de casi todo lo lúgubre de su atmósfera: "nos haces una falta sin fondo" (verso 2) y "cae sombra en el alma" (verso 17). Se trata de imágenes paralelas en cuanto que ambas representan un intento de dar dimensiones imposibles a determinado tipo de elementos (falta-fondo/sombra-alma. Castro Arenas estudia ésta y otras fórmulas retóricas de Vallejo, como oxímoron, catacresis y antítesis. Más adelante habrá ocasión de confirmar su idea de que la catacresis "reside en la médula del estilo vallejiano"3). Pero además, una relación parecida a la que se ha deducido más atrás puede reproducirse aquí: si el verso segundo es una definición de la muerte ("falta sin fondo"), el verso 17 es su consecuencia ("cae sombra en el alma"), de donde se concluye que en estos dos versos no se interrumpe el proceder general del poema.

La evidencia del tema de la muerte, tan manifiesto en esa ruptura de patrones, puede encubrir excesivamente una dimensión menos obvia, pero más trascendente, por lo que se refiere a la poética de Vallejo: el problema de la dualidad. La crítica, en general, tiende a separarlo del de la muerte y a abstraerlo hasta darle forma de concepto filosófico. Tal desdoblamiento y/o elaboración no parece existir en ninguno de los textos que se estudian en este trabajo, si tenemos en cuenta que el mismo vehículo (personas y tiempos verbales, en este primer caso) por el que se nos comunica el tema de la muerte, nos trae inseparablemente su dimensión de dualidad. En definitiva, la clave mayor de "A mi hermano Miguel" no es otra que un respeto a ultranza de la distancia más insalvable (y la más tradicionalmente reconocida): la distancia del yo

2 André Coyné, César Vallejo, Buenos Aires, 1968, pp. 83 a 87.

3 Mario Castro Arenas, "Algunos rasgos estilísticos de la poesía de César Vallejo", en Imagen de la literatura peruana actual, ed. Julio Ortega (Lima, 1968), t. I, p. 185 . 
al tú. Precisamente, la clave del poema "Alfonso: estás mirándome, lo veo..." es la opuesta: un intento, por los medios que sea, de anular esa distancia (que es sólo una proyección de la distancia yo - mí mismo) cuya manifestación más rotunda es la muerte.

Aquel respeto de "A mi hermano Miguel" por la dualidad yo/tú no pudo encontrar mejor forma de expresión que las personas verbales. A este respecto dice Benveniste:

Las expresiones de la persona verbal están en su conjunto organizadas por dos correlaciones constantes:

1) Correlación de personalidad, que opone las personas yo/tu a la nopersona/él;

2) correlación de subjetividad, anterior a la precedente, y que opone yo a tú.

La distinción ordinaria de singular y plural debe ser, si no reemplazada, sí cuando menos interpretada en el orden de la persona, por una distinción entre persona estricta (= "singular") y persona amplificada (= "plural"). Unicamente la tercera persona, por ser no-persona, admite un verdadero plural4.

La correlación de subjetividad dispone las personas verbales de las dos primeras estrofas: estoy-haces / escondo-des / ocultas-doy. En cuanto a la primera persona del plural, hemos de tener en cuenta que "en nosotros es siempre yo quien predomina ... los componentes no equivalen uno a otro" $"$. Es el dominio de la primera persona en las dos primeras estrofas, a que me he referido más atrás. Ahora bien, esta primera persona, al llegar a la tercera estrofa, se refugia en "la no-persona", el él ("se ha aburrido"), mientras el tu aislado domina ("escondiste", "estabas"). La correlación de personalidad sustituye a la de subjetividad para, en definitiva, acentuar la dualidad entre los dos personajes.

Ambas correlaciones de personas verbales encuentran también su proyección en otros elementos del texto: en la segunda estrofa se hace un uso poco frecuente en español del pronombre sujeto, "yo ... tú . . tú ... yo ...". Al "yo" protagonista de la acción le acompaña el adverbio "antes" (verso 6); al "tú" protagonista le acompaña "después" (verso 9). Esta misma dualidad parece afectar a las formas temporales, de tal manera que los pasados "jugábamos", "hacíamos" vienen a marcar, respecto al presente, la misma distancia insalvable que se manifiesta entre el yo y el tú. En la tercera estrofa (que comienza, precisamente, "Miguel, tú"), junto a la ausencia de la palabra "juego" y de la primera persona dominante, y la inversión de tiempos, que va del pasado al presente (en lugar del presente al pasado, como antes), encontramos la expresión "tu gemelo corazón": dos corazones de los que se destaca tanto el parecido como la dualidad, lo mismo que viene a señalar el término "hermano", en el penúltimo verso del poema. Incluso la metáfora en que se nos comunica el proceso de la muerte se caracteriza fundamentalmente por apoyarse en esa dualidad: en el juego del escondite la base

4 Emile Benveniste, Problemas de lingüistica general, México, 1972, p. 171.

5 Ibid., p. 169. 
es que alguien se esconda y alguien busque al escondido; el juego se termina con el encuentro de ambos. En el poema "A mi hermano Miguel" ese encuentro no se produce; la muerte ha estancado definitivamente la marcha del juego, congelando la dualidad que trataba de ser eliminada.

El intento de destruir esa dualidad de la que la lengua es el agente trasmisor da lugar a toda la dificultad que lleva consigo la lectura del segundo poema. "Alfonso: estás mirándome, lo veo...", casi entre los últimos Poemas humanos, tiene cincuenta versos y está dividido en seis estrofas, consiguientemente mucho más largas que las de "A mi hermano Miguel". Entre uno y otro poema está el libro completo de Trilce y casi todos los Poemas humanos. Esa distancia que va del primero al último libro ha sido medida, en primer lugar, en términos geográficos y sentimentales, tomando como punto de partida precisamente las "Canciones del hogar": "one of the central obsessions ... that begins to emerge from the poems of Heraldos negros, and which is developed with a far more eloquent anguish in his next book, Trilce (1922), is the memory of one single traumatic act: Vallejo's departure from his family up in Santiago del Chuco, and his consecuent initiation into worldliness"'. Coyné centra todo su estudio de Trilce en torno al tema de la orfandad y ausencia del hogar, que le parece el elemento capital, hasta el punto de que "en Poemas humanos ya dijimos que dos textos, por lo menos - "Gleba" y, principalmente, "Telúrica y magnética"- acumularán todavía referencias al terruño de la infancia"7. Este punto de vista lo comparten otros muchos autores; valga de ejemplo el caso de Sucre que, en una visión general de la poesía de Vallejo, desarrolla como tesis principal la de que "Vallejo es poeta en el exilio. Desterrado de su morada, de su verdadero reino, vive errante: no sólo geográfica, sino también, y sobre todo, espiritualmente"8.

No estoy nada seguro de que se trate, en último término, de una nostalgia, una partida del hogar o una orfandad; en definitiva, París, como explicaré, si es lugar de destierro, lo es bienamado, sin merecer reproches, mereciendo más bien alabanzas y entusiasmo de parte del "desterrado", que hasta quiso que le enterraran en el cementerio de Montrouge. Parece más bien que lo que hay detrás de ese tema o temas es otra vez la dualidad, en este caso dualidad temporal (pasado/presente) y de la persona (yo/tú; él es la no-persona), como se ha visto ya en "A mi hermano Miguel" y se verá más adelante. La distancia que habría entre uno y otro poema es más bien la que va del uso incuestionable de esa dualidad a su destrucción o su aniquilamiento en una unidad. La crítica, en general, ha circunscrito el tema de la dualidad a los Poemas humanos y lo describe así: "El hombre, tal y como aparece en Poemas humanos, es un ser que aspira a la unidad y se ve condenado a la dualidad, un ser que sufre un deterioro de su condición hasta que la

6 D. P. Gallagher, op. cit., p. 15.

7 ANDRÉ CoYné, op. cit., p. 70.

8 Gullermo Sucre, "Vallejo, la nostalgia de la inocencia", Sur, 1968, p. 3. 
división llega a la desintegración completa"9. Ahora bien, en la trayectoria recorrida desde "A mi hermano Miguel" hasta "Alfonso: estás mirándome, lo veo...", hay una serie de pasos bastante definidos que conducen a esa abierta creación de la unidad. En primer lugar, aquella separación del juego, mantenida por la muerte, acaba resolviéndose en soledad desde el tercer poema de Trilce:

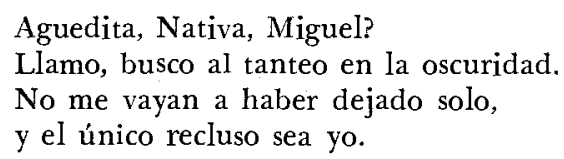

EI "juego", que vuelve a asomar en Trilce, interesa aún como signo de los tiempos y con mayor claridad que en los Heraldos negros ("jugar ... pero todo de engaños, de candor, como fue", Trilce, XI), si bien hay ya un intento de dominar la dualidad de los tiempos verbales denunciándola, descubriendo al pasado y al futuro su carácter falso, su inexistencia:

Lo hacia de engaños...

más ya lo sabes: todo fue mentira.

$\mathrm{Y}$ sigues llorando, bueno, pues!

Otra vez ni he de verte cuando juegues. (LI)

En otras palabras, sin aludir expresamente al juego: "no será lo que aún no haya venido, sino / lo que ha llegado y ya se ha ido, / sino lo que ha Ilegado y ya se ha ido" (XXXIII). EI poyo de la casa, que venía a ser como el fetiche centralizador de toda la historia en "A mi hermano Miguel", vuelve a hacer acto de presencia en Trilce, en el poema que guarda, quizá, más estrecha relación con él y con las otras "Canciones del hogar", el LXI (a Sucre le parece que es más bien el poema III, y a Higgins el LXV). En su nueva aparición, el "poyo" de la casa no sólo descubre abiertamente su carácter fetichista, conciliador de imágenes y sentimientos, sino que aparece rodeado de unos tiempos verbales opuestos entre sí de forma radical, estridente (pretérito indefinido/presente de subjuntivo), sin la flexibilidad o ambigüedad armónica de aquella primera elegía, a la que tanto recuerda (presente de indicativo/pretérito imperfecto de indicativo); estamos en el momento clave de la denuncia o fijación de la dualidad que tiene lugar todo a lo largo de Trilce:

el poyo en que mamá alumbró

al hermano mayor para que ensille

Iomos que había yo montado en pelo,

por rúas y por cercas, niño aldeano;

9 James Higgrns, Visión del hombre y de la vida en las uiltimas obras poéticas de César Vallejo, México, 1970, p. 241. El tema es estudiado en las páginas 223 a 241. Con palabras muy semejantes se expresa Juan LARrea, César Vallejo o Hispanoamérica en la cruz de su razón, Córdoba, 1957, p. 24; Xavier Abril, César Vallejo o la teoria poética, Madrid, 1963, le dedica un capítulo (pp. 87 a 92). 
el poyo en que dejé que se amarille al sol mi adolorida infancia... (LXI)

Es bien sabido cómo entre la escritura de Trilce y la de los Poemas humanos pasó mucho tiempo y hubo acontecimientos definitivos que marcaron la vida del poeta y su poesía. De todos ellos interesa, sobre todo, aquí, su traslado a París y su instalación prácticamente definitiva en esa ciudad. Así como habíamos visto las "Canciones del hogar" arropadas por un determinado contexto geográfico-humano de casa paterna y pueblo de Perú, París va a ocupar ese lugar para los nuevos poemas y, por lo tanto, para "Alfonso: estás mirándome, lo veo...". La distancia entre los dos contextos geográficos queda determinada en las primeras líneas de Poemas en prosa, libro que apareció precediendo a Poemas humanos en una primera edición común (1939): "Hay, madre, un sitio en el mundo que se llama París. Un sitio muy grande y lejano y otra vez grande" ("El buen sentido"). A veces puede surgir un conflicto entre los dos contextos (como en "Fue domingo en las claras orejas de mi burro...", donde, en el enfrentamiento, los burros representan al Perú y la estatua de Voltaire a París), pero, por regla general, el nuevo contexto no es tratado como un lugar de destierro, trágico o amargo. Así, la primera vez que se menciona "París" en Poemas humanos (en "Hoy me gusta la vida mucho menos...") se hace del siguiente modo:

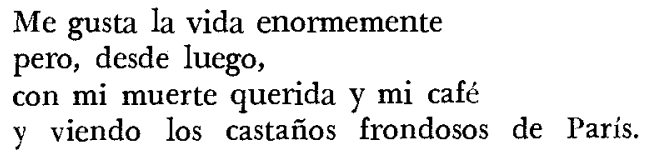

Sobre este nuevo contexto, la dualidad, respetada, casi sobreentendida en "A mi hermano Miguel", puesta al desnudo en Trilce, va a tratar de ser destruida en Poemas humanos. El paso del respeto a la destrucción, es decir, de la dualidad a la unión, nos es comunicado, en primer lugar, con el cambio que se produce de aquel relativamente sencillo enfrentamiento de significantes (tiempos y personas de los verbos) que tiene, tal vez, su máxima expresión en Trilce LXI, a un enfrentamiento de significados, relegando los significantes a un segundo término de importancia informativa. Este paso se anuncia con bastante claridad en Trilce; por ejemplo, en el poema III se lee: "busco al tanteo"; "buscar" y "tantear" no se oponen; la combinación de significados sigue una lógica tradicional. Ahora bien, en el poema XXIII se lee: "oirá en tu silenciar"; ya hay una oposición manifiesta en oír lo callado, pero relativamente poco innovadora; recuerda, por ejemplo, bastante de cerca, los versos de San Juan de la Cruz, "la música callada, la soledad sonora". Este intento de trabar en una unidad de significado dos elementos supuestamente inconciliables aparece conseguido en casi todos los Poemas humanos, muchas veces en enumeraciones arrolladoras, como las "Yuntas" del segundo poema del libro, o esta otra que tiene también varios puntos de contacto con la elegía a Alfonso de Silva: 
Y entonces oirás cómo medito,

y entonces tocarás cómo tu sombra es esta mía desvestida

y entonces olerás cómo he sufrido

("Pero antes que se acabe...")

De "oler" y "sufrir" importa decididamente su significado mucho más que el tiempo o la persona. Estas dualidades aunadas son el recurso básico de Poemas humanos y aparecen por doquier:

caigo altamente...

salen a mi encuentro los que aléjanse.

('Escarnecido, aclimatado al bien....")

acompañarme a estar solo

("De disturbio en disturbio...")

nada, en verdad, más ácido, más dulce

("A lo mejor soy otro...")

Las formas estrictamente verbales han cedido su predominio; interesan, en primer lugar, los significados.

Muy integrado en el conjunto de los Poemas humanos, sin pertenecer a ningún grupo tan concreto como el de "Canciones del hogar", "Alfonso: estás mirándome, lo veo..." viene a formar parte del cabo opuesto, dentro de ese proceso de la dualidad, en cuyo otro extremo se sitúa "A mi hermano Miguel"10. En primer lugar, aquel contexto de "hogar", cuidadosamente descrito ("sala", "zaguán", "corredores"), es sustituido del todo y con color equivalente por "París" ("rue de Ribouté", "boite de nuit ... monsieur Fourgat", "Hôtel des Ecoles"). En segundo lugar, los términos verbales y su concierto de dobles personas y tiempos, han cedido el lugar a parejas de significados que tratan de unir sentidos contrarios; de aquella combinación de la primera estrofa, "estoy, nos haces, me acuerdo, jugábamos, nos acariciaba", viene a esta otra: "estás mirándome/lo veo, siempres/jamases, tu sueño/mi sueño", que no es radicalmente distinta de la anterior si tenemos en cuenta que allí había una oposición yo-tú/antes-ahora, que se ha resuelto aquí en un encuentro de mirar-ver/siempre-jamás/tu sueño-mi sueño, en un intento de romper aquella dualidad impuesta por las formas verbales. Estos encuentros de significados continúan dominando el resto del poema en la forma que voy a mostrar.

La segunda estrofa contiene elementos que pueden contraponerse con facilidad a los de "A mi hermano Miguel":

$$
\begin{array}{ll}
\text { París } & - \text { casa } \\
\text { tu inolvidable cholo } & - \text { tu gemelo corazón } \\
\text { por mí, por ti } & - \text { nos } \\
\text { brindar por la profundidad } & - \text { falta sin fondo } \\
\text { último acto } & - \text { oraciones vespertinas }
\end{array}
$$

10 La crítica no ha destacado particularmente el poema. Le prestan alguna atención Higgins, op. cit., p. 313, y José María VALverde en el primer trabajo de su libro Estudios sobre la palabra poética, Madrid, 1952, cuando se reficre al tema de la muerte. 
Sin embargo, todos esos elementos temáticos se encajan en una red de oposiciones muy distantes de la primera elegía: palpablemente/oye, te siente/callar, toca/último acto (ver). No importa tanto que palpablemente sea adverbio y oye tercera persona del presente de indicativo del verbo oír, cuanto que el primero significa el sentido del tacto y el segundo el del oído, y que esa dualidad quiere ser unificada. Lo mismo podemos decir de las demás parejas.

Como en el caso de "A mi hermano Miguel", la tercera estrofa expone abiertamente el tema de la vida frente a la muerte como máximo exponente de la dualidad yo-tú. En primer lugar, cada uno de los componentes de la dualidad aparece a su vez dividido en dos: el yo es "mi alma" más alguien "bajo mi abrigo", y su dualidad trata de unirse "bajo el rayo simple de la sien compuesta"; el tú es el "ser" más el "estar" y tal dualidad trata de unirse en los "ceros de madera". Ahora bien, si el sufrimiento es signo de "vida", como se puede comprobar todo a lo largo de Poemas humanos, el "ser" y el "estar" son ambos "tumbas", según se da a entender más adelante en el poema (quinta estrofa, versos 34,35 y 36$)$. Por el momento, sin embargo, se mantiene, en cierto sentido, la dualidad, mientras que a partir de la quinta estrofa tratará de ser borrada por medios definitivos.

La cuarta estrofa se centra en el $t u ́$ y su correspondiente dualidad: tú es tu criatura + su corazón, tú + escolta de ti mismo, tú + llorando por ti, tú + tu sombra. Los últimos tres versos de la estrofa, tal y como los entiendo, parecen referirse a una anécdota: Alfonso, muerto, ya no puede comunicarse ("¿Decírselo? ¿Contárselo?") con monsieur Fourgat: "ya no". Por lo tanto, de alguna manera, la dualidad (distancia entre el muerto que fue y el vivo que es) se sigue manteniendo.

Las dos últimas estrofas tratan de llevar a cabo la unión, la disolución de esa dualidad, entrelazando tres diferentes caminos que le son habituales a Vallejo: la unión "vida := muerte", el número tres, la comunión ritual. Las parejas de opuestos se inician con un signo de vida ("sufrir") y una apoyatura contradictoria de ese signo ("dulcemente") ; es una construcción morfológicamente paralela a la de "palpablemente oír" de la segunda estrofa. Pero en esa iniciación se da al mismo tiempo otra unión contradictoria más sutil: "te digo", al muerto, "recordando" la vida ("Io que hemos sufrido"); el "recordar" que regresa al pasado (muerto) y el "decir" en presente (vida). Después de esta doble pareja, la insistencia de tres adjetivos ("ambos", "ambos", "doble"), asociados a tres palabras que tienen tanto - y tan poco- en común como "sufrido" (vida = muerte), "muerte" (¿muerte = vida?) y "tumba" (la del ser $=$ vida, la del estar $=$ muerte) crean esa atmósfera de unión decidida entre la vida y la muerte, entre un yo-vida y un tú-muerte. El patrón "sufro/recordando/hubimos" se repite de nuevo en los últimos versos de la estrofa: "sufro/bebiendo/decíamos", pero ya no conduce a la unión por la conciliación vida $=$ muerte $/$ muerte $=$ vida, sino que introduce un nuevo tipo de unión, la comunión ritual: "bebiendo un vaso de ti". En este caso, además, esa liturgia del comulgante va acompañada por un cierto sentido de carpe diem que no es infrecuente en 
Vallejo. Ya en Trilce LXX se lee: "Amemos las actualidades / que / siempre no estaremos como estamos". Más tarde, en Poemas humanos, el tema se repite, pero con alusión directa a "vida" y "muerte": “. . p pasemos un instante la vida / a dos vidas y dando a una parte nuestra muerte" ("Palmas y guitarras"). En "Alfonso: estás mirándome, lo veo..." el tema resulta menos obvio y al mismo tiempo de mayor alcance: "bebiendo un vaso ... y después, ya veremos"; pero se trata de un vaso "para ponerse bien" al mismo tiempo que es un vaso de muerte ("de ti"): la comunión ritual envuelve al vivo y al muerto, otra vez, como lo había hecho la unión anterior del sufrimiento-muerte-tumba de ambos.

La última estrofa se abre con una especie de enigma: el tema de la comunión se continúa en un "brindis", con todas sus connotaciones profanas, pero se le añade una nueva dimensión: "entre tres". La presencia de este número en la poesía de Vallejo ha sido interpretada por la crítica de forma algo abstrusa: "La tendencia a resolver en un orbe absoluto la dualidad antinómica por medio de un tercer término dinámico que se traduce con frecuencia en emoción, en lirismo"11. O bien: "EI número tres suele ser símbolo de unidad y armonía"12. El mismo Vallejo, algunos años después de publicar Trilce, ya asentado en París (1926), se refiere al número tres en forma nada fácil de descifrar: "Hacedores de metáforas, no olvidéis que las distancias se anuncian de tres en tres"13. La red de relaciones con que el número tres aparece localizado en el poema es la siguiente:

\author{
brindis \\ entre tres / taciturno / diverso \\ en vino / en mundo / en vidrio \\ brindábamos \\ más de una vez / menos de una vez \\ cuerpo / pensamiento
}

En cierto sentido esta distribución no es tan radicalmente distinta de aquella otra que habíamos visto en las personas y los tiempos verbales de "A mi hermano Miguel", donde los tres elementos en juego eran: la madre, yo y tú. ¿Cuáles son aquí los tres elementos? ¿Yo, tú, Cristo? Más bien parece que se trata de una forma de conciliación de opuestos, la más quintaesenciada, si se quiere, que no existía de ningún modo, en aquel otro poema: el yo y el $t \dot{u}$ pueden reducirse a numerales como se han reducido a sustantivos y adjetivos inconciliables; el número dos es supuestamente irreducible a la unidad; el uno, el dos y el tres, com. binados sin mayor razón, se sitúan por encima de esa irreductibilidad e intercambian sus significados.

En "A mi hermano Miguel" la contraposición de tiempos verbales,

11 Juan Larrea, op. cit., p. 26.

12 James Higgins, op. cit., p. 311.

13 Publicado primero en su revista parisina Favorables, Paris, Poema, está reco. gido, con otros ensayos, en Literatura y arte (textos escogidos), Buenos Aires, 1966 , p. 22. 
y el dominio final del presente de indicativo son anunciados en el primer verso por el adverbio "hoy", entre otras maneras; en "Alfonso: estás mirándome, lo veo...", el "hoy" va a introducir los últimos versos (repetido dos veces) haciendo referencia, también, al primer verso de la primera estrofa, que lleva sus dos verbos en presente ("estás... veo"). Lo que ese "hoy" introduce ("Hoy es más diferente todavía") es una última, definitiva progresión en el intento de anular la dualidad; en primer lugar, la disposición de parejas, después del dulce/amargo del sufrir (vida), es tanto sintagmática como paradigmática, con una organización de geometría minuciosa:

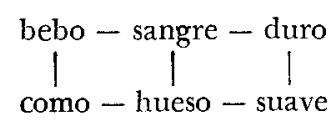

En segundo lugar, la presencia de "Cristo", asociada a comer y beber, da a la comunión ritual una nueva dimensión sacramental, mesiánica, incluso. Ya en "La rueda del hambriento", una a manera de conversión de piedras en pan tiene resonancias de un episodio evangélico (Mat., 4 , 3) que los exégetas han interpretado como un anuncio de la consagración de la Ưltima Cena. En el último de los Poemas humanos ("Ello es que el lugar donde me pongo...") el tema de la consagración - transustanciación y comunión- surge de nuevo:

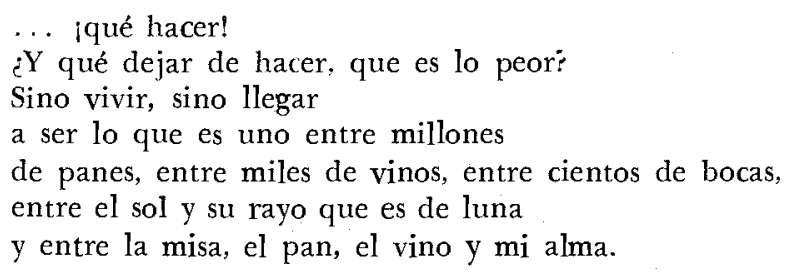

Pero donde alcanza un desarrollo más detallado es en "Alfonso: estás mirándome, lo veo...": se nombra a Cristo y se mencionan, reelaboradas, las palabras rituales de la liturgia de la misa (Luc., 22, 19 y ss.). La doctrina católica enseña dos cosas con respecto al sacramento: primero, que esa entrega - transustanciación- de Cristo, es la máxima prueba de amor concebible ("porque te quiero", dice Vallejo); y segundo, que el acto de la consagración se prolongará para siempre, hasta la consumación de los siglos (el "eternamente" de Vallejo), venciendo a la muerte. Los dos últimos versos, comparados con los dos últimos de "A mi hermano Miguel", se alejạn radicalmente de aquella congelación de la dualidad en el presente, consumando una unidad. Su "dos a dos" ya había sido utilizado y explicado en "Palmas y guitarras": "saldremos de nosotros, dos a dos" con el fin de vivir "un instante la vida a dos vidas". Se cierra completamente el ciclo unificador del poema, desde el momento en que el "dos a dos" y el "eternamente" resumen la contraposición de la primera estrofa: 


$$
\begin{aligned}
& \text { estás mirándome/lo veo - "dos a dos" } \\
& \text { tu sueño/mi sueño } \\
& \text { siempres/jamases }
\end{aligned}
$$

Un punto más de contacto y de distancia entre los dos poemas. Habíamos visto que en "A mi hermano Miguel" la muerte aparecía indicada desde el primer momento por una serie de indicios, lo mismo que la vida. Sin embargo, los términos "muerte" y "vida" no aparecen ni una sola vez, con una especie de supersticiosa ausencia que coincide con el respeto por la dualidad tradicional que allí se observa. Indicios de vida y muerte tampoco faltan todo a lo largo de "Alfonso: estás mirándome, lo veo...", sobre todo si se considera al poema en su contexto de Poemas humanos y no simplemente aislado: el "sufrimiento" y el "dolor" del vivir se repite continuamente como los "siempres" y, sobre todo, los "jamases" (hasta el "qué jamás de jamases", en "Piensan los viejos asnos...") de la muerte. Algunos de los indicios de la muerte son incluso comunes a los dos poemas: del "nos hacíamos llorar" al "llorando por ti mismo" hay, como indicios, muy poca distancia; algo semejante se puede decir de la "falta sin fondo" y el "brindar por la profundidad", en uno y otro poema. Incluso es posible, en cierto modo, asociar los últimos versos de ambos poemas, en cuanto que "no tardes en salir" y "casi lo podría decir, eternamente" vienen a significar tipos de intento de solución al conflicto que da lugar al poema, el de la vida frente a la muerte. Ahora bien, la antigua superstición ha desaparecido en la última elegía, y es posible mencionar el término "muerte". En esa mención, que aumenta la larga distancia entre las dos elegías, aparece además resumido todo el sentido del poema, la disolución de la dualidad: la "muerte" (como también "la tumba") no es la del amigo, sino la de ambos, la muerte que comienza en el nacimiento (" $1 \mathrm{Haber}$ nacido para vivir de nuestra muerte!", en "Y si después de tantas palabras...") y resuelve en una tumba "doble" el ser de los vivos y el estar de los muertos; la "muerte" en definitivo singular de un "ambos" que sólo puede ser plural.

Princeton University.

Luis Fernández Cifuentes.

\section{APÉNDICE}

\section{A MI HERMANO MIGUEL}

\section{In memoriam}

Hermano, hoy estoy en el poyo de la casa, donde nos haces una falta sin fondo! Me acuerdo que jugábamos esta hora, y que mamá nos acariciaba: "Pero, hijos..."

5 Ahora yo me escondo, como antes, todas estas oraciones 
vespertinas, y espero que tú no des conmigo.

Por la sala, el zaguán, los corredores.

Después, te ocultas tú, y yo no doy contigo.

10 Me acuerdo que nos hacíamos llorar, hermano, en aquel juego.

Miguel, tú te escondiste una noche de agosto, al alborear; pero, en vez de ocultarte riendo, estabas triste.

$15 \mathrm{Y}$ tu gemelo corazón de esas tardes extintas se ha aburrido de no encontrarte. $Y$ ya cae sombra en el alma.

Oye, hermano, no tardes en salir. Bueno? Puede inquietarse mamá.

\section{ALFONSO: ESTAS MIRANDOME, LO VEO...}

Alfonso: estás mirándome, lo veo,

desde el plano implacable donde moran

lineales los siempres, lineales los jamases.

(Esa noche, dormiste, entre tu sueño

5 y mi sueño, en la rue de Ribouté)

Palpablemente

tu inolvidable cholo te oye andar

en París, te siente en el teléfono callar

y toca en el alambre a tu último acto

10 tomar peso, brindar

por la profundidad, por mí, por ti.

Yo todavía

compro "du vin, du lait, comptant les sous"

bajo mi abrigo, para que no me vea mi alma,

15 bajo mi abrigo aquel, querido Alfonso,

y bajo el rayo simple de la sien compuesta;

yo todavía sufro, y tú, ya no, jamás, hermano!

(Me han dicho que en tus siglos de dolor, amado sér,

20 amado estar,

hacías ceros de madera. ¿Es cierto?)

En la "boite de nuit", donde tocabas tangos, tocando tu indignada criatura su corazón, escoltado de ti mismo, llorando

25 por ti mismo y por tu enorme parecido con tu sombra, monsieur Fourgat, el patrón, ha envejecido.

¿Decírselo? ¿Contárselo? No más,

Alfonso; eso, ya no!

El hotel des Ecoles funciona siempre

30 y todavía compran mandarinas;

pero yo sufro, como te digo, 
dulcemente, recordando

lo que hubimos sufrido ambos, a la muerte de ambos, en la apertura de la doble tumba,

35 de esa otra tumba con tu sér, y de ésta de caoba con tu estar; sufro, bebiendo un vaso de ti, Silva, un vaso para ponerse bien, como decíamos, y después, ya veremos lo que pasa...

40 En éste el otro brindis, entre tres, taciturno diverso en vino, en mundo, en vidrio, al que brindábamos más de una vez al cuerpo, $y$, menos de una vez, al pensamiento.

45 Hoy es más diferente todavía; hoy sufro dulce, amargamente, bebe tu sangre en cuanto a Cristo el duro, como tu hueso en cuanto a Cristo el suave, porque te quiero, dos a dos, Alfonso,

50 y casi lo podría decir, eternamente. 